\title{
Industrial Developments in Automa Cytology
}

0001-5547/96/4001-0025/\$02.00/0 (c) The International Academy of Cytology

Acta Cytologica

Introduction

The structure of the presentations is as follows:

I. Description of the General Aims of the System

II. Description of the Hardware and Software

III. Current Status and Testing

IV. Future Trends Envisioned by the Industrial

Developer

V. References

Represented are:

AccuMed International, Inc., Chicago, Illinois, U.S.A.

CompuCyte Corporation, Cambridge, Massachusetts, U.S.A.

CYTYC Corporation, Marlborough, Massachusetts, U.S.A.

NeoPath, Inc., Redmond, Washington, U.S.A.

Neuromedical Systems, Inc., Suffern, New York, U.S.A.

Roche Image Analysis Systems, Inc., Elon College, North Carolina, U.S.A.

Xillix Technologies Corporation, Vancouver, B.C., Canada

For further details direct inquiries to the individual corporations and/or attend:

Fourth International Conference on the

Computerized Cytology and Histology Laboratory

March 17-20, 1996

Drake Hotel, Chicago.

The conference office may be reached at fax: 312-

947-0290. 